\title{
Hidratação controlada de sementes de soja: potencial fisiológico e emergência em solo com Rhizoctonia solani
}

\author{
Denis Santiago da Costa ${ }^{1}$, Cartiane Rubishirley de Macedo Rocha ${ }^{2}$, Juliana Tieme Yagushi ${ }^{2}$, \\ José Otávio Machado Menten², Ananias Alves Cruz ${ }^{3}$
}

\author{
${ }^{1}$ Universidade Estadual de Londrina, Centro de Ciências Agrárias, Londrina, Paraná, Brasil. E-mail: denisccauel@gmail.com \\ ${ }^{2}$ Universidade de São Paulo, Escola Superior de Agricultura "Luiz de Queiroz”, Piracicaba, São Paulo, Brasil. E-mail: \\ cartirocha@yahoo.com.br, juty@gmail.com, jom@usp.br \\ ${ }^{3}$ Universidade do Estado do Amazonas. Escola Superior de Tecnologia, Manaus, Amazonas, Brasil. E-mail: ananiasac@ @otmail.com
}

Recebido: 21/11/2016; Aceito: 04/05/2017.

\section{RESUMO}

A hidratação controlada é uma técnica que favorece a germinação rápida e uniforme diminuindo o tempo de contato entre fungos responsáveis pelo tombamento de plântulas e os tecidos suscetíveis. Assim, objetivou-se avaliar diferentes métodos de hidratação controlada de sementes de soja, seus efeitos sobre o potencial fisiológico das sementes e sobre emergência em solo infestado por Rhizoctonia solani. Três lotes de sementes de soja do cultivar BRS 232 foram avaliados e classificados quanto à germinação e ao vigor e, em seguida, submetidas à procedimentos de hidratação controlada (controle, entre papéis com água destilada, entre papéis com água destilada com PEG 6000 e por imersão direta em solução aquosa de PEG 6000). A eficiência dos tratamentos foi avaliada pela germinação, primeira contagem, comprimento de plântulas, índice de vigor, além da emergência em solo infestado por $R$. solani. Conclui-se que sementes de soja submetidas à hidratação controlada entre papéis com água destilada emitem a raiz primária mais rapidamente com plântulas apresentando maior comprimento e índice de vigor. A presença de $R$. solani no solo reduz a emergência de plântulas de soja, não sendo a hidratação controlada uma alternativa para o controle.

Palavras-chave: Glycine max L., tombamento de plântulas, PEG 6000

\section{Hydration controlled in soybean seeds: physiological potential and emergence in soil with rhizoctonia solani}

\begin{abstract}
Hydration controlled is a technique that favors fast and uniform seed germination and reduce the contact time between fungi responsible for damping-off and susceptible tissues of seedlings. The objective of this research was to evaluate different hydrations methods of soybean seeds, their effects on seed physiological potential and emergence in soil infested with Rhizoctonia solani. Three lots of soybean cultivar BRS 232 were evaluated and classified as germination and vigor and then submitted to hydration methods (control, between papers in water, between papers in PEG 6000 and direct immersion in PEG 6000). The treatments were evaluated by germination, first germination count, seedling length, vigor index and emergence in soil infested with $R$. solani. It was concluded that soybean seeds submitted to hydration controlled between papers in water protrude the primary root faster with seedlings showing greater length and vigor index. The presence of $R$. solani in soil reduces soybean seedlings emergence not being the hydration controlled an alternative for the control.
\end{abstract}

Key words: Glycine max L., damping off, PEG 6000 


\section{Introdução}

No Brasil, a infecção por Rhizoctonia solani Kühn é um problema recorrente nas lavouras das principais culturas, sendo considerado um dos patógenos mais importantes no cultivo da soja. Dentre seus prejuízos nas principais culturas, podem ser citados a ocorrência de mela, resultando em menor área fotossintética (BASSETO et al., 2007), e o tombamento de plantas, resultando em população de plantas abaixo da recomendada (ALMEIDA et al., 2005). O tombamento é causado por lesões profundas nas plântulas, podendo ocorrer antes ou após a emergência; as condições ideais para o desenvolvimento da doença são temperatura entre 15 e $18{ }^{\circ} \mathrm{C}$ e umidade do solo de moderada a alta (ALMEIDA et al., 2005).

Por ser um fungo muito agressivo e de difícil controle, recomenda-se aos produtores o manejo adequado da cultura, com a adoção de práticas culturais que visem minimizar a ação desse patógeno sobre as plantas. Devido à baixa eficiência da rotação de culturas (REIS et al., 2011) e a ampla ocorrência de hospedeiro (POLONI et al., 2016), as práticas culturais mais utilizadas para o controle desse patógeno são a utilização de microrganismos para biocontrole (BASSETO et al., 2008) e o tratamento com fungicida (CHITARRA et al., 2009; GOULART, 2006).

Tratamentos preventivos de plantas são de fundamental importância na agricultura, pois previnem ou retardam o aparecimento da doença. Uma forma de prevenção é o uso de sementes sadias as quais são indispensáveis para o controle de algumas doenças por prevenir a disseminação de patógenos no espaço e no tempo. Sementes de alta qualidade também apresentam germinação rápida e uniforme não permitindo o contato prolongado entre patógeno e semente, desfavorecendo o processo de infecção. Portanto, técnicas que acelerem e uniformizem a germinação dos lotes poderia ser uma alternativa para retardar a infecção nas lavouras das principais culturas.

O condicionamento fisiológico é uma técnica que consiste na hidratação das sementes sob condições controladas, visando estimular o metabolismo e os processos fisiológicos durante as fases I e II de embebição para acelerar a germinação (BRADFORD, 1986). Além de ativar o metabolismo das sementes, essa técnica permite que ocorra a restauração da integridade do sistema de membranas perdida durante o processo de secagem das sementes, evitando ocorrência de maior liberação de açúcares, aminoácidos e nutrientes que poderiam servir de substrato para desenvolvimento de microrganismo (CASTRO; HILHORST, 2004).

Osburn e Schroth (1988) observaram haver uma estreita relação entre a quantidade de nutrientes lixiviados das sementes e a ocorrência do tombamento de plântulas. Verificaram que a colonização das plântulas por Pythium ultimum Trow estava diretamente relacionada com a quantidade de equivalente em glicose liberada pelas sementes de beterraba durante a germinação e que, ao aplicar a técnica de condicionamento físiológico, a quantidade de açúcar liberada era reduzida, bem como a colonização pelo patógeno. Similar a esses resultados, El-Mohamedy e El-Baky (2008) verificaram que o condicionamento fisiológico das sementes reduziu o tombamento de plântulas de ervilha, causado por Fusarium solani (Mart.) Sacc. Sclerotium rolfsii Sacc. e Rhizoctonia solani Kühn, em 11,7\%, $14,2 \%$ e $10,0 \%$, respectivamente.

Assim, objetivou-se avaliar métodos de hidratação controlada de sementes de soja, seus efeitos sobre o desenvolvimento de plântulas e sobre emergência em solo infestado por Rhizoctonia solani.

\section{Material e Métodos}

Sementes de soja (Glycine max L.) do cultivar BRS 232, representadas por três lotes foram submetidas a caracterização quanto ao teor de água inicial, à germinação e ao vigor (primeira contagem de germinação, envelhecimento acelerado, emergência de plântulas e condutividade elétrica das sementes), conforme descritos a seguir:

Teor de água: determinado pelo método da estufa a $105^{\circ} \mathrm{C}\left( \pm 3^{\circ} \mathrm{C}\right)$, durante $24 \mathrm{~h}$ (BRASIL, 2009), em duas sub-amostras por lote de 4,5 g $\pm 0,5 \mathrm{~g}$ sendo os resultados expressos em percentagem (base úmida) para cada lote.

Teste de germinação: conduzido com quatro repetições de 50 sementes para cada lote, em rolos de papel Germitest ${ }^{\circledR}$ umedecidos com quantidade de água destilada equivalente a 2,5 vezes a massa do substrato seco e mantidas a $25{ }^{\circ} \mathrm{C}$ em germinador do tipo Mangelsdorf durante oito dias sob luz contínua. A interpretação de plântulas normais foi realizada de acordo com as recomendações das Regras para Análise de Sementes (BRASIL, 2009) e os resultados expressos em percentagem de plântulas normais para cada lote.

Primeira contagem de germinação: realizada com o registro da porcentagem de plântulas normais no quinto dia após a semeadura durante o teste de germinação.

Envelhecimento acelerado: as sementes foram distribuídas em camada única sobre uma tela de alumínio e colocadas em caixas de plástico $(11 \times 11 \times 3,5 \mathrm{~cm})$, contendo $40 \mathrm{~mL}$ de água destilada, sem que as sementes entrassem em contato com a água. $\mathrm{O}$ envelhecimento foi realizado a $41^{\circ} \mathrm{C}$, durante $48 \mathrm{~h}$ (BAALBAKI et al., 2009) em câmara de envelhecimento jaquetada, seguido do teste de germinação, conforme descrito anteriormente. Aos 5 dias foram registradas as porcentagens de plântulas normais. 
Emergência de plântulas: conduzido em casa de vegetação onde foram distribuídas em caixas contendo areia lavada quatro repetições de 50 sementes para cada lote; a disponibilidade de água do substrato foi ajustada para $60 \%$ da sua capacidade de retenção, conforme Brasil (2009). No décimo quarto dia após a semeadura foi registrada a porcentagem total de plântulas que atingiram, pelo menos, o estádio de primeira folha totalmente expandida.

Condutividade elétrica: conduzido de acordo com o procedimento contido em Baalbaki et al. (2009). Quatro sub-amostras de 50 sementes fisicamente puras de cada lote foram previamente mesuradas por suas massas e em seguida imersas em $75 \mathrm{~mL}$ de água destilada, a $25^{\circ} \mathrm{C}$, durante $24 \mathrm{~h}$. Decorrido esse período, a condutividade elétrica da solução foi determinada em condutivímetro de bancada e os resultados expressos em $\mu \mathrm{S} \mathrm{cm}^{-1} \mathrm{~g}^{-1}$.

A análise dos dados de caracterização dos lotes foi realizada em delineamento inteiramente ao acaso com quatro repetições e os dados obtidos submetidos a análise de variância para verificação da significância pelo teste F. Quando o fator de variação se apresentou significativo, a pelo menos $5 \%$ de probabilidade, aplicou-se o teste de Scott-Knott para comparação das médias.

Após a caracterização inicial dos lotes um experimento foi instalado em esquema fatorial $3 \times 4$, sendo três lotes de sementes de soja e quatro modos de hidratação controlada (controle, entre papéis com água, entre papéis com água com PEG 6000 e imersão direta em solução aquosa de PEG 6000), com quatro repetições por tratamento.

A hidratação controlada entre papéis com água foi realizada distribuindo-se as sementes de soja entre duas camadas constituídas de três folhas de papel Germitest ${ }^{\circledR}$ cada, umedecidas com quantidade de água destilada equivalente a 2,5 vezes a massa do papel seco, e mantidas em câmara de germinação a $20{ }^{\circ} \mathrm{C} \pm 1{ }^{\circ} \mathrm{C}$, durante o período necessário para que as mesmas atingissem o teor de água de aproximadamente $35 \%$ (Fase II da curva de embebição). Esse valor foi adotado e obtido em função do teor de água inicial e por meio de verificação da massa de sementes (COSTA et al., 2013).

Para a hidratação controlada entre papéis com solução de PEG foi realizada a distribuição das sementes de soja entre duas camadas de três folhas de papel Germitest ${ }^{\circledR}$ cada, umedecidas com quantidade de solução de polietilenoglicol (PEG 6000) equivalente a 2,5 vezes a massa do papel seco. O potencial osmótico utilizado para elevar o teor de água das sementes foi de -0,8 MPa, obtido por meio da dissolução de PEG 6000, de acordo com Villela et al. (1991). Posteriormente, as sementes foram mantidas em germinador regulado a $20{ }^{\circ} \mathrm{C}$ pelo período necessário para atingir o teor de água de aproximadamente $35 \%$, valor obtido pelo acompanhamento do ganho de massa das sementes. Esse valor foi identificado conforme proposto anteriormente. Após a retirada das sementes do tratamento efetuou-se uma série de três lavagens por 1 minuto em água corrente para retirar resíduos de PEG que poderiam estar aderidos nas sementes.

A hidratação controlada por imersão direta foi realizada pela distribuição das sementes em um recipiente contendo solução aquosa de PEG 6000, sob bombeação constante de oxigênio a $20^{\circ} \mathrm{C}$ no escuro em câmara de germinação, durante período necessário para atingir o teor de água de aproximadamente 35\%, conforme proposto anteriormente, sendo esse valor obtido pelo acompanhamento do ganho de massa das sementes. O potencial osmótico utilizado foi de $-0,8$ $\mathrm{MPa}$, obtido de modo similar para a hidratação controlada entre papéis com solução de PEG. Após a retirada das sementes da solução osmótica, efetuou-se uma série de três lavagens por um minuto em água corrente.

As sementes obtidas após os tratamentos foram imediatamente caracterizadas quanto à germinação (conforme descrito anteriormente) e ao vigor, por meio do comprimento de plântula e índice de vigor obtidos por meio da análise de imagens de plântulas.

A análise de imagem de plântulas foi realizada por meio de quatro repetições de 25 sementes para cada lote e tratamentos onde as sementes de soja foram colocadas para germinar em rolo de papel Germitest ${ }^{\circledR}$ a $25{ }^{\circ} \mathrm{C}$, durante três dias (MARCOS-FILHO et al., 2009). As plântulas obtidas de cada repetição foram transferidas do papel Germitest ${ }^{\circledR}$ para uma folha de cartolina preta $(30 \times 22 \mathrm{~cm})$ e as imagens obtidas por meio de um scanner HP Scanjet G2410, operado por Software Photosmart, com resolução de 100 dpi. As imagens digitalizadas foram analisadas no software Seed Vigor Imaging System (SVIS). Os parâmetros obtidos pelo programa foram o comprimento de plântulas (CP), em centímetros e o índice de vigor (IV), que é baseado na média ponderada referente a $70 \%$ do crescimento das plântulas e $30 \%$ da uniformidade do lote.

Adicionalmente, dentro de cada lote, foi proposto um esquema fatorial $4 \times 2$, sendo quatro técnicas de hidratação controlada das sementes (controle, entre papéis com água destilada, entre papéis com água destilada com PEG 6000 e por imersão direta em solução aquosa de PEG 6000) e duas condições de solo infestado por $R$. solani (ausência ou presença), com quatro repetições. Para a infestação do solo, colônias puras do fungo isoladas de plantas de soja foram repicadas para placas de petri contendo o meio de cultura batata-dextrose-ágar (BDA) onde permaneceram por 7 dias em câmara de incubação sob temperatura de $20 \pm 2{ }^{\circ} \mathrm{C}$ sob fotoperíodo de luz branca de $12 \mathrm{~h}$ por dia. As colônias formadas foram trituradas, em 
liquidificador, adicionando-se $50 \mathrm{~mL}$ de água destilada para cada placa, até obter uma suspensão líquida homogênea. Essa suspensão foi adicionada em solo autoclavado e úmido contido em caixas de $43 \times 30 \times 11$ $\mathrm{cm}$, na quantidade de $75 \mathrm{~mL}$ para cada caixa; $24 \mathrm{~h}$ após a inoculação foi realizada a semeadura e as caixas mantidas em casa de vegetação (SOUZA et al., 2007). Após, cessar o processo de emergência, fez-se a contagem do número de plântulas emersas aos 14 dias após a instalação do teste obtendo-se a porcentagem de emergência de plântulas.

Os dados obtidos foram testados quanto as pressuposições do modelo matemático e submetidos a análise de variância e avaliado pelo teste F; quando o valor de $\mathrm{F}$ foi significativo ao nível de $5 \%$ de probabilidade realizou-se a comparação das médias pelo teste de Scott-Knott (5\%).

\section{Resultados e Discussão}

De acordo com os resultados de caracterização, foi observado que as sementes de soja de todos os lotes estavam com teores de água inicial similares (Tabela 1), fato esse fundamental para a pesquisa em tecnologia de sementes, pois permite inferir que as sementes apresentavam, no momento das análises, um nível de metabolismo semelhante e que as variações observadas entre os lotes foram, exclusivamente, devido às diferenças de potencial fisiológico.

A germinação das sementes de soja foi similar entre os três lotes, no entanto, as análises complementares ao teste de germinação possibilitaram estabelecer uma classificação quanto ao potencial fisiológico (Tabela 1). Foi identificado que o lote L-01 foi superior aos lotes L-
02 e L-03 para os testes de envelhecimento acelerado, emergência de plântulas e condutividade elétrica (Tabela 1). O lote L-02 foi o que apresentou o menor número de plântulas emersas na emergência em condições de casa de vegetação (EP), indicando conter sementes menos vigorosas entre todos os lotes.

Após as sementes serem submetidas aos modos de hidratação controlada foi observado que os teores de água variaram entre $31,2 \%$ e $33,4 \%$ (Tabela 2), valores próximos ao objetivo inicial (35\%). Os dados analisados em esquema fatorial (Tabela 3) evidenciaram haver interação entre hidratação controlada $\times$ lote para teste de germinação e primeira contagem $(\mathrm{p}<0,01)$ enquanto que para o comprimento de plântula e índice de vigor se observou apenas efeito do condicionamento ( $\mathrm{p}<0,01)$. Após as sementes serem submetidas aos modos de hidratação controlada foi observado que os teores de água variaram entre $31,2 \%$ e $33,4 \%$ (Tabela 2), valores próximos ao objetivo inicial (35\%).

Além disso, a IDP reduziu também o número de plântulas normais para o lote L-02, indicando que no lote que continha sementes menos vigorosas esse processo pode ser prejudicial a germinação.

O menor desempenho das plântulas sob a hidratação controlada por imersão direta em solução aquosa de PEG 6000 foi atribuído aos efeitos do dano por embebição pois, conforme constatado na caracterização, as sementes apresentavam baixo teor de água para todos os lotes no momento da aplicação do tratamento. De acordo com Silva e Villela (2011) sementes de soja quando muito secas e submetidas a hidratação resultam em menor número de plântulas normais e maiores valores de condutividade elétrica, caracterizando o dano por embebição.

Tabela 1. Caracterização inicial quanto ao teor de água (T.A), teste de germinação (G), primeira contagem de germinação (PC), teste de envelhecimento acelerado (EA), emergência de plântulas (EP) e a condutividade elétrica (CE) de três lotes de sementes de soja, cultivar BRS 232

\begin{tabular}{|c|c|c|c|c|c|c|}
\hline \multirow{2}{*}{ Lotes } & T.A. & G & $\mathrm{PC}$ & EA & EP & \multirow{2}{*}{$\begin{array}{c}\mathrm{CE} \\
\left(\mu \mathrm{S} \mathrm{cm}^{-1} \mathrm{~g}^{-1}\right)\end{array}$} \\
\hline & & & $(\%)$ & & & \\
\hline L-01 & 8,5 & $94 \mathrm{a}$ & $90 \mathrm{a}$ & $76 \mathrm{a}$ & $90 \mathrm{a}$ & $123,9 \mathrm{a}$ \\
\hline L-02 & 8,6 & $88 \mathrm{a}$ & $87 \mathrm{a}$ & $68 \mathrm{~b}$ & $68 \mathrm{c}$ & $149,2 \mathrm{~b}$ \\
\hline L-03 & 8,4 & $90 \mathrm{a}$ & $90 \mathrm{a}$ & $67 \mathrm{~b}$ & $85 \mathrm{~b}$ & $140,5 \mathrm{~b}$ \\
\hline C.V.(\%) & - & 2,2 & 1,7 & 3,4 & 3,4 & 2,8 \\
\hline
\end{tabular}

* Letras minúsculas iguais nas colunas não diferem a 5\% de significância pelo teste de Scott-Knott.

Tabela 2. Graus de umidade obtidos para sementes de soja após a aplicação de diferentes modos de hidratação controlada, cultivar BRS 232.

\begin{tabular}{lllll}
\hline \multirow{2}{*}{ Lotes } & \multicolumn{4}{c}{ Grau de umidade das sementes $(\%)$} \\
\cline { 2 - 5 } & Controle & EPH & EPP & IDP \\
\hline L-01 & 8,5 & 33,0 & 31,2 & 33,2 \\
L-02 & 8,6 & 32,0 & 31,9 & 32,2 \\
L-03 & 8,4 & 33,4 & 31,3 & 32,7 \\
\hline
\end{tabular}

Hidratação controlada: EPH: entre papéis com água; EPP: entre papéis com PEG; IDP: imersão direta com PEG. 
Tabela 3. Resumo do quadro de análise de variância (quadrado médio) para teste de germinação (G), primeira contagem de germinação (PC), comprimento de plântula (COMP) e índice de vigor (IV) em três lotes de sementes de soja submetidos a diferentes modos de hidratação controlada, cultivar BRS 232

\begin{tabular}{lllll}
\hline \multirow{2}{*}{ Fonte de variação } & \multicolumn{3}{c}{ Características } \\
\cline { 2 - 5 } & $\mathrm{G}$ & $\mathrm{PC}$ & $\mathrm{COMP}$ & $\mathrm{IV}$ \\
\hline Hidratação controlada (HC) & $264,56^{* * *}$ & $605,86^{* * *}$ & $51,21^{* * *}$ & $250007,7^{* * *}$ \\
Lotes (L) & $111,00^{* * *}$ & $102,30^{* * *}$ & $1,52^{\text {n.s. }}$ & $9778,3^{\text {n.s. }}$ \\
HC $\times \mathrm{L}$ & $74,22^{* *}$ & $114,70^{* * *}$ & $0,21^{\text {n.s. }}$ & $1531,1^{\text {n.s. }}$ \\
Resíduo & 20,22 & 24,8 & 0,76 & 5103,3 \\
\hline Média geral & $88 \%$ & $82 \%$ & $7,11 \mathrm{~cm}$ & 736 \\
C.V. $(\%)$ & 5,12 & 6,06 & 12,26 & 9,71 \\
\hline
\end{tabular}

significativo a $1 \%$ pelo teste $\mathrm{F}{ }^{\text {n.s. }}$ não significativo pelo teste $\mathrm{F}$.

De acordo com os resultados da análise de imagem de plântulas, foi observado que a hidratação controlada entre papéis com água (EPH) promoveu maiores valores de comprimento de plântulas e índice de vigor (Figuras $1 \mathrm{C}$ e 1D), revelando os benefícios da aplicação dessa técnica, independente do potencial fisiológico inicial do lote utilizado; nesse caso, a EPH aumentou a velocidade de emissão da raiz primária resultando em expressão de maior comprimento e do índice de vigor dos lotes. As técnicas de hidratação controlada entre papéis com PEG 6000 (EPP) ou de imersão direta em PEG 6000 (IDP) evidenciaram resultados similares ou negativos em relação à testemunha, respectivamente (Figura $1 \mathrm{C}$ e 1D), semelhante ao observado anteriormente para germinação e primeira contagem (Figura 1A e 1B).

Os resultados de comprimento de plântulas e índice de vigor foram mais sensíveis do que o teste de germinação e primeira contagem para indicar os benefícios da hidratação controlada aos lotes de sementes. De acordo com Vanzolini et al. (2007) o comprimento de plântulas é um teste eficaz para classificar lotes de alto potencial fisiológico e com diferenças sutis de vigor, diferentemente da germinação que somente avalia a normalidade das plântulas; ao refletir a maior taxa de crescimento, o comprimento de plântula indica haver potencial de desenvolvimento mais rápido das plântulas e, portanto, estabelecimento adequado em campo. Além disso, a associação entre o comprimento de plântula e a uniformidade dos lotes de sementes por meio do índice de vigor tem sido uma eficiente avaliação do potencial fisiológico com resultados coerentes para diversas espécies, tais como milho-doce, soja e feijão (ALVARENGA et al., 2012; GOMES-JÚNIOR et al., 2014; GOMES-JÚNIOR et al., 2009; MARCOS-FILHO et al., 2009).
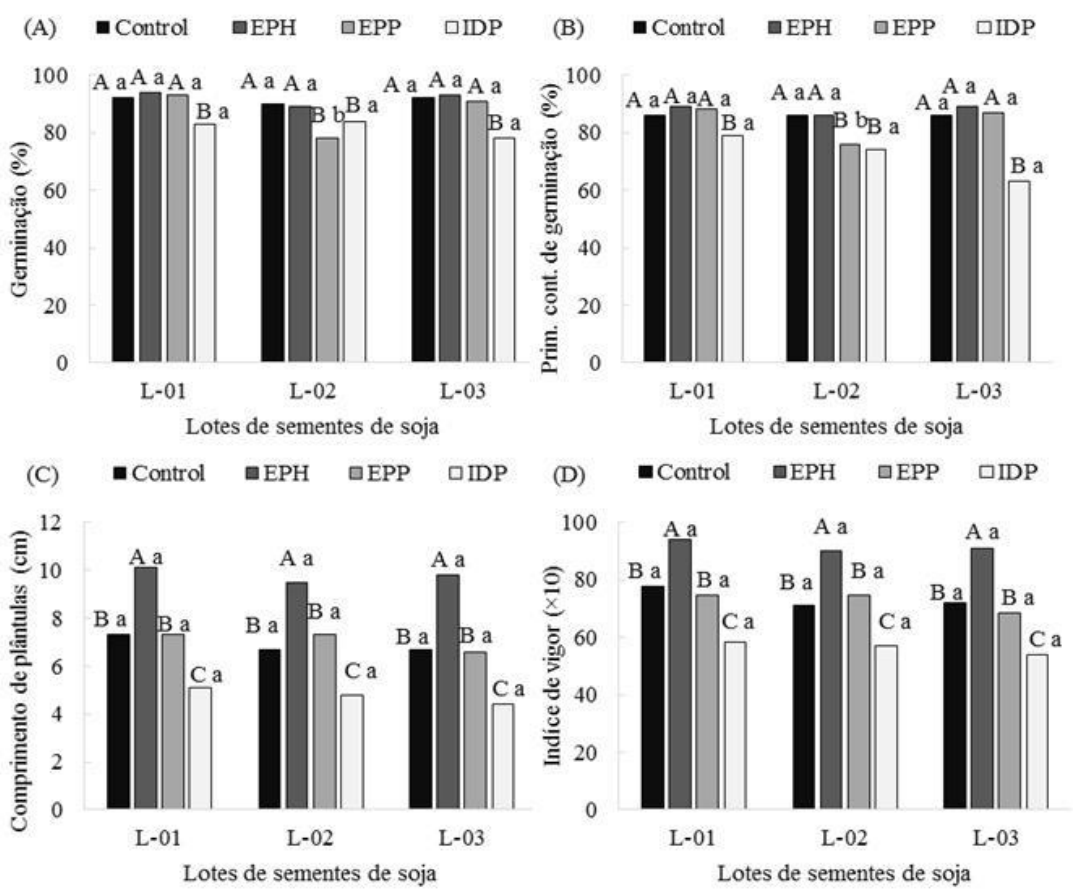

Figura 1. Germinação (A.), primeira contagem (B.), comprimento de plântulas (C.) e índice de vigor (D.) de três lotes de sementes de soja, submetidos a quatro tratamentos de hidratação controlada: controle, entre papéis com água (EPH), entre papéis com PEG 6000 (EPP) e imersão direta em PEG (IDP). Letras maiúsculas distintas significam diferenças pelo teste de Scott-Knott entre modos de hidratação dentro de cada lote e minúsculas distintas entre lote dentro de cada modo de hidratação. 


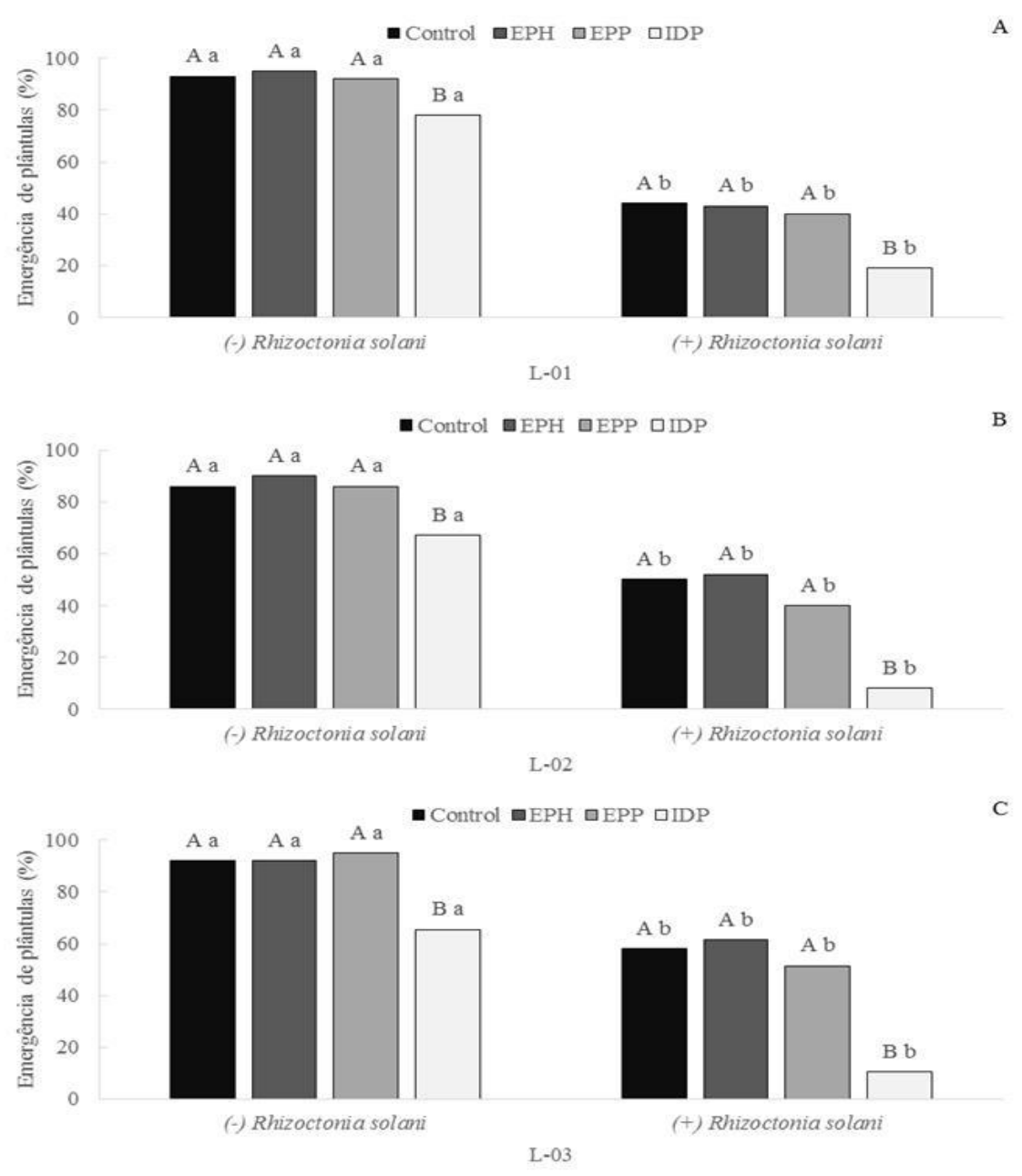

Figura 2. Emergência de plântulas de três lotes de sementes de soja L-01, L-02 e L-03 (A, B e C, respectivamente) submetidos a diferentes técnicas de hidratação controlada, em solo com (+) e sem (-) infestação por $R$. solani. Letras maiúsculas distintas significam diferenças entre os modos de hidratação dentro de cada infestação e minúsculas distintas diferenças entre presença e ausência do fungo dentro de cada modo de hidratação pelo teste de Scott-Knott à $5 \%$ de significância. Control= controle; EPH= hidratação controlada entre papéis com água; EPP= hidratação controlada entre papéis com PEG 6000; IDP= hidratação controlada por imersão direta em PEG 6000.

A técnica de hidratação controlada com secagem ou não das sementes após o tratamento (condicionamento fisiológico) tem sido destacada como benéfica para a soja em outras linhas de pesquisa, principalmente quando realizada em hidrocondicionamento, conforme observado por diversos autores (COSTA et al., 2013; GIURIZATTO et al., 2008; SADEGUI et al., 2011). Como aplicação, essa técnica pode ser realizada por melhoristas visando uniformizar o florescimento de diferentes genótipos e aumentar a eficiência dos cruzamentos ou para aplicação em pequena escala, uma vez que está associada a incrementos de produtividade (SILVA et al., 2016). Quanto ao uso da hidratação controlada a fim de aumentar a emergência das plântulas em solo infestado por R. solani, constatou-se que nenhum tratamento foi eficiente no estabelecimento superior de plântulas (Figura 2A, 2B e 2C), sendo que a presença do fungo no solo reduziu significativamente $\mathrm{o}$ número de plântulas normais, independente do lote e da técnica aplicada às sementes. Os resultados negativos obtidos com a técnica de imersão direta em solução de PEG 6000 (IDP), já observados através dos parâmetros germinação, primeira contagem, comprimento e índice de vigor, repetiram-se neste experimento reafirmando problemas com essa técnica para sementes de soja. Ressalta-se que, na presença de $R$. solani, todos os lotes apresentaram germinação inferior à da ausência desse patógeno, fato atribuído a agressividade do patógeno.

Ainda que a técnica de condicionamento tenha apresentado resultados benéficos em outras pesquisas com outros patógenos, ressalta-se que não se trata de um controle $100 \%$ efetivo (EL-MOHAMEDY; EL-BAKY, 2008). Rush (1991), estudando o efeito do condicionamento de sementes de beterraba no controle de $P$. ultimum presente no solo, verificou que houve uma redução no número de plântulas tombadas, porém com controle parcial do tombamento. No caso da soja, verificou-se que nem no lote de maior vigor (L-01) e tampouco no de menor vigor (L-02) os tratamentos favoreceram a germinação na presença desse patógeno. 


\section{Conclusões}

Sementes de soja submetidas à hidratação controlada entre papéis com água destilada emitem a raiz primária mais rapidamente com plântulas apresentando maior comprimento e índice de vigor. A presença de $R$. solani no solo reduz a emergência de plântulas de soja, não sendo a hidratação controlada uma alternativa para o controle.

\section{Agradecimentos}

Os autores agradecem à Dr. Maria Heloisa Duarte de Moraes pelo auxílio nas técnicas laboratoriais bem como na ajuda da elaboração do manuscrito.

\section{Referências Bibliográficas}

ALMEIDA, A. M. R.; FERREIRA, L. P.; YORINORI, J. T.; SILVA, J. F. V; HENNING, A. A.; GODOY, C. V; COSTAMILAN, L. M.; MEYER, M. C. Doenças da soja. In: KIMATI, H.; AMORIM, L.; REZENDE, J. A. M.; BERGAMIN-FILHO, A.; CAMARGO, L. E. A. (Ed.). Manual de fitopatologia - Doenças da Plantas Cultivadas. 4. ed. São Paulo-SP: Editora Agronômica Ceres, 2005. p. 570588 .

ALVARENGA, R. O.; MARCOS-FILHO, J.; GOMESJUNIOR, F. G. Avaliação do vigor de sementes de milho superdoce por meio da análise computadorizada de imagens de plântulas. Revista Brasileira de Sementes, Londrina-PR, v. 34, n. 3, p. 488-494, 2012.

BAALBAKI, R.; ELIAS, S.; MARCOS-FILHO, J.; MCDONALD, M. B. Seed vigor testing handbook. Contributi ed. Ithaca, NY, USA: AOSA, 2009.

BASSETO, M. A.; CERESINI, P. C.; VALÉRIO FILHO, W. V. Severidade da mela da soja causada por Rhizoctonia solani AG-1 IA em função de doses de potássio. Summa Phytopathologica, Botucatu-SP, v. 33, n. 1, p. 56-62, 2007.

BASSETO, M. A.; VALÉRIO FILHO, W. V.; SOUZA, E. C.; CERESINI, P. C. O papel de Rhizoctonia spp. binucleadas na indução de resistência a mela da soja. Acta Scientiarum. Agronomy, Marinagá-PR, v. 30, n. 2, p. 183-189, 2008.

BRADFORD, K. J. Manipulation of seed water relations via osmotic priming to improve germination under stress conditions. HortScience, Alexandria, v. 21, n. 5, p. 11051112,1986

MAPA/BRASIL. MINISTÉRIO DA AGRICULTURA, PECUÁRIA E ABASTECIMENTO. Regras para análise de sementes. Brasília-DF: Secretaria de Defesa Agropecuária, 2009.

CASTRO, R. D.; HILHORST, H. W. M. Embebição e reativação do metabolismo. In: FERREIRA, A. G.; BORGHETTI, F. (Ed.). Germinação: do básico ao aplicado. Porto Alegre-RS: Artmed, 2004. p. 149-162.

CHITARRA, L. G.; GOULART, A. C. P.; ZORATO, M. F. Tratamento de sementes de algodoeiro com fungicidas no controle de patógenos causadores de tombamento de plântulas. Revista Brasileira de Sementes, Londrina-PR, v. 31, n. 1, p. 168-176, 2009.

COSTA, D. S.; BONASSA, N.; NOVEMBRE, A. D. L. C. Incidence of storage fungi and hydropriming on soybean seeds. Journal of Seed Science, Londrina-PR, v. 35, n. 1, p. 35-41, 2013.

EL-MOHAMEDY, R. S. R.; EL-BAKY, M. M. H. A. Evaluation of different types of seed treatment on control of root rot disease, improvement growth and yield quality of pea plant in Nobaria Province. Research Journal of Agriculture and Biological Sciences, Konstitutcii, v. 4, n. 6, p. 611-622, 2008.

GIURIZATTO, M. I. K.; ROBAINA, A. D.; GONÇALVES, M. C.; MARCHETTI, M. E. Qualidade fisiológica de sementes de soja submetidas ao hidrocondicionamento. Acta Scientiarum. Agronomy, Maringá-PR, v. 30, n. 5, p. 711717, 2008

GOMES-JUNIOR, F. G.; CHAMMA, H. M. C. P.; CICERO, S. M. Automated image analysis of seedlings for vigor evaluation of common bean seeds. Acta Scientiarum. Agronomy, Maringá-PR, v. 36, n. 2, p. 195, 2014.

GOMES-JUNIOR, F. G.; MONDO, V. H. V; CICERO, S. M.; MCDONALD, M. B.; BENNETT, M. A. Evaluation of priming effects on sweet corn seeds by SVIS. Seed Technology, Lincoln, v. 31, n. 1, p. 95-100, 2009.

GOULART, A. C. P. Efeito do tratamento de sementes de algodoeiro com fungicidas no controledo tombamento em relação à densidade de inóculo de Rhizoctonia solani. Summa Phytopathologica, Botucatu-SP, v. 32, n. 4, p. 360-366, 2006

MARCOS-FILHO, J.; KIKUTI, A. L. P.; LIMA, L. B. Métodos para avaliação do vigor de sementes de soja, incluindo a análise computadorizada de imagens. Revista Brasileira de Sementes, Londrina-PR, v. 31, n. 1, p. 102-112, 2009.

OSBURN, R. M.; SCHROTH, M. N. Effect of osmopriming sugar beet seed on exudation and subsequent damping-off caused by Pythium ultimum. Phytopathology, Saint Paul, v. 78 , n. 9 , p. $1246-1250,1988$

POLONI, N. M.; MOLINA, L. M. R.; MESA, E. C.; GARCIA, I. L.; CERESINI, P. C. Evidência de que o fungo Rhizoctonia solani AG-1 IA adaptado à Urochloa na Colômbia mantém ampla gama de hospedeiros incluindo o milho. Summa Phytopathologica, Botucatu-SP, v. 42, n. 3, p. 228-232, 2016.

REIS, E. M.; CASA, R. T.; BIANCHIN, V. Control of plant disease by crop rotation. Summa Phytopathologica, Botucatu-SP, v. 37, n. 3, p. 85-91, 2011.

RUSH, C. M. Comparison of seed priming techniques with regard to seedling emergence and Pythium damping-off in sugar beet. Phytopathology, Saint Paul, v. 81, n. 8, p. 878882,1991

SADEGHI, H.; KHAZAEI, F.; YARI, L.; SHEIDAEI, S. Effect of seed osmopriming on seed germination behavior and 
vigor of soybean (Glycine max L.). Journal of Agricultural and Biological Science, Islamabad, v. 6, n. 1, p. 39-43, 2011.

SILVA, T. A.; SILVA, P. B.; SILVA, E. A. A.; NAKAGAWA, J.; CAVARIANI, C. Condicionamento fisiológico de sementes de soja, componentes de produção e produtividade. Ciência Rural, Santa Maria-RS, v. 46, n. 2, p. 227-232, 2016.

SILVA, K. R. G.; VILLELA, F. A. Pré-hidratação e avaliação do potencial fisiológico de sementes de soja. Revista Brasileira de Sementes, Londrina-PR, v. 33, n. 2, p. 331-345, 2011.

SOUZA, E. C.; KURAMAE, E. E.; NAKATANI, A. K.; BASSETO, M. A.; PRABHU, A. S.; CERESINI, P. C. Caracterização citomorfológica, cultural, molecular e patogênica de Rhizoctonia solani Kühn associado ao arroz em Tocantins, Brasil. Summa Phytopathologica, Botucatu-SP, v. 33 , n. 2, p. 129-136, 2007.
VANZOLINI, S.; ARAKI, C. A. S.; SILVA, A. C. T. M. ; NAKAGAWA, J. Teste de comprimento de plântula na avaliação da qualidade fisiológica de sementes de soja. Revista Brasileira de Sementes, Londrina-PR, v. 29, n. 2, p. 90-96, 2007.

VILLELA, F. A.; FILHO, L. D.; SEQUEIRA, E. L. Tabela de potencial osmótico em função da concentração de polietileno glicol 6.000 e da temperatura. Pesquisa Agropecuária Brasileira, Brasília-DF, v. 26, n. 11/12, p. 1957-1968, 1991. 